\title{
Taxas de risco de acidentes de trabalho no Brasil: efeito do Fator Acidentário de Prevenção (FAP)?
}

\author{
Risk rates of workplace accidents in Brazil: \\ effect of the Accidental Prevention Factor (APF)?
}

\author{
Amanda da Rosa Wernke (https://orcid.org/0000-0002-0616-5899) ${ }^{1}$ \\ Manuella Caroline Luchtenberg Teixeira (https://orcid.org/0000-0002-1710-790X) ${ }^{1}$ \\ Beatriz de Oliveira Kock (https://orcid.org/0000-0002-1833-5234) ${ }^{1}$ \\ Olga Luiza Oliveira Sousa (https://orcid.org/0000-0001-6651-343X) ${ }^{1}$ \\ Ana Carolina Macedo Carvalho de Melo (https://orcid.org/0000-0002-0325-9080) ${ }^{1}$ \\ Thiago Mamoru Sakae (https://orcid.org/0000-0002-0603-3685) ${ }^{1}$ \\ Flávio Ricardo Liberali Magajewski (https://orcid.org/0000-0003-2092-9610) ${ }^{1}$
}

${ }^{1}$ Curso de Medicina,

Universidade do Sul de

Santa Catarina (UNISUL).

Av. José Acacio Moreira 787,

Dehon, Campus Tubarão.

88704-900 Tubarão SC

Brasil.

magajewski@hotmail.com

\begin{abstract}
Historically, the conflict of interests between employers and workers obliged the State to assume the role of regulating this relationship, instituting laws and overseeing the application of health and safety standards at work. The Accident Prevention Factor (FAP) is one of these guidelines. This article aims to analyze the correlations between the FAP and the risk rate for occupational accidents in Brazil in the period between 2006 and 2016. Ecological study, which analyzed the occupational accidents, registered in the Brazilian Social Security database in the period between 2006 and 2016. The analysis included the calculation of accident risk rates according to the Brazilian regions, divisions of the CNAE, reason/situation, ICD-10 chapters, sex and age. The comparison between results from the two periods was performed using the average risk rates from the two periods using Student $t$ test, Spearman correlation and beta value. Basically, all rate series analyzed had a strong downward trend in the FAP period, contrary to what occurred in the immediately previous period.
\end{abstract}

Key words Occupational health, Occupational accidents, Risk factors
Resumo A ocorrência de acidentes e de doenças relacionadas ao trabalho são expressões concretas da exposição dos trabalhadores aos riscos presentes no ambiente laboral. Historicamente o conflito de interesses entre empregadores e trabalhadores obrigou o Estado a assumir a função de regulação desta relação, instituindo leis e fiscalizando a aplicação das normas de saúde e segurança no trabalho. O Fator Acidentário de Prevenção (FAP) é uma dessas estratégias. O objetivo deste artigo é analisar a correlação entre as taxas de risco de acidentes de trabalho no Brasil antes (2006-2009) e depois (2010-2016) da vigência do FAP. Estudo ecológico com análise temporal de séries de taxas de acidentes de trabalho registrados nas bases de dados da Previdência Social no período 2006 e 2016. A análise incluiu o cálculo das taxas de risco de acidentes segundo grandes regiões brasileiras, divisões do CNAE, motivo/situação, capitulos do CID-10, sexo e idade. A comparação entre os resultados dos dois períodos foi realizada utilizando-se as taxas de risco médias com a aplicação do teste t de Student e da correlação de Spearman. Basicamente todas as séries de taxas analisadas obtiveram forte tendência de redução no período de vigência do FAP, ao contrário do que ocorreu no período imediatamente anterior.

Palavras-chave Saúde do Trabalhador, Comunicação de acidentes de trabalho, Fatores de risco 


\section{Introdução}

O conceito de trabalho historicamente foi associado a algo penoso e carregado de sofrimento. O próprio termo trabalho tem origem do latim tripalium, que designava um instrumento de tortura utilizado pelos antigos romanos. Como o trabalho era considerado um castigo, os nobres e os senhores feudais se recusavam a trabalhar, impondo essa atividade aos servos e escravos ${ }^{1}$.

No entanto, essa perspectiva sofreu grandes transformações ao longo do tempo, e foi fortemente determinada pelos avanços tecnológicos incorporados aos processos produtivos. $\mathrm{O}$ trabalho moderno pode ser conceituado como "toda energia física ou intelectual empregada pelo homem com finalidade produtiva"'; pressupondo assim, um esforço físico ou mental com a finalidade de alcançar um resultado.

No modo de produção capitalista, a centralidade das relações de trabalho e seu potencial de conflito exigiram gradativamente a constituição de um marco regulatório amplo com a finalidade de garantir a dignidade dos trabalhadores sem prejudicar o seu potencial de produtividade ${ }^{1,2}$. Desde sua fundação, em 1919, a Organização Internacional do Trabalho procura produzir consenso entre os países em relação à promoção e harmonização dos direitos do trabalho por meio do estabelecimento e aplicação de normas internacionais de saúde e segurança do trabalho. Um exemplo deste protagonismo pode ser observado no conteúdo da Convenção 155, de 1981, que enfatizou a proteção da saúde dos trabalhadores nos ambientes de trabalho, e relacionou iniciativas de prevenção à ocorrência de acidentes do trabalho e de responsabilização dos empregadores pelo cumprimento de normas, padrões de segurança e higiene no trabalho tanto no âmbito individual quanto coletivo ${ }^{2}$.

De acordo com o art. 19 da Lei no 8.213/1991, o acidente de trabalho pode ser caracterizado como aquele que ocorre pelo exercício do trabalho a serviço da empresa ou pelo exercício do trabalho, desde que provoque como resultado uma lesão corporal ou perturbação funcional que cause a morte, perda ou redução da capacidade para o trabalho, seja ela temporária ou permanente ${ }^{3}$.

O legislador determinou, no art. 20 da Lei $\mathrm{n}^{\circ} 8.213 / 1991$, a equiparação de determinadas morbidades ao acidente de trabalho $^{3}$, citando especificamente a doença profissional, assim entendida como aquela produzida ou desencadeada pelo exercício do trabalho peculiar a determinada atividade; e a doença do trabalho, compreendida como aquela adquirida ou desencadeada em função de condições especiais em que o trabalho é realizado e com ele se relacione diretamente. Além disso, dispõe expressamente o $\$ 2^{\circ}$ : “Em caso excepcional, constatando-se que a doença não incluída na relação prevista nos incisos I e II deste artigo resultou das condições especiais em que o trabalho é executado e com ele se relaciona diretamente, a Previdência Social deve considerá-la acidente do trabalho"3,4. Em outras palavras, uma doença poderá ser enquadrada como acidente do trabalho toda vez que estiver comprovado o nexo causal entre uma morbidade incapacitante e as condições em que o trabalho era executado.

Os acidentes de trabalho, além dos prejuízos provocados aos trabalhadores, geram custos tanto para o Estado quanto para o empregador. Em casos mais graves, o Instituto Nacional do Seguro Social (INSS) é responsável pelo pagamento de benefícios, como auxílio doença acidentário, auxílio acidente, habilitação e reabilitação profissional e pessoal, aposentadoria por invalidez e pensão por morte ${ }^{4,5}$. O empregador por sua vez sofre com repercussões de ordem jurídica, econômica, social e previdenciária. O contratante deixa de contar com a mão de obra temporariamente indisponível, além de arcar com custos em casos de acidentes menos graves, já que é o responsável direto pelo pagamento do salário dos trabalhadores afastados por motivo de saúde até o décimo quinto $\operatorname{dia}^{4-6}$.

A partir de 2010, as empresas também foram oneradas ou bonificadas pela ocorrência de acidentes de trabalho em patamares acima ou abaixo da média da atividade econômica a que estão inseridas, visto que a sua frequência, gravidade e custo afeta o cálculo do Fator Acidentário de Prevenção (FAP) da empresa, nos termos do art. 10 da Lei no ${ }^{\circ} 10.666 / 2003^{6}$.

O FAP foi originado após anos de debate do Ministério do Trabalho e da Previdência Social, que buscavam flexibilizar as alíquotas do pagamento do Seguro de Acidente do Trabalho (SAT), que correspondem a 1,2 ou 3\% da folha de pagamento de acordo com o grau de risco da empresa, multiplicando-as de acordo com a magnitude dos danos e o impacto econômico dos acidentes de trabalho ocorridos em cada empresa, como uma estratégia de estímulo às empresas para a melhora das condições de trabalho ${ }^{7,8}$. Simplificadamente, as empresas são ordenadas em três grandes grupos ou tercis, que agregam as empresas do mesmo código de atividade econômica conforme um índice de cálculo que leva em 
consideração as variáveis de frequência, gravidade e custo dos acidentes de trabalho ocorridos. As empresas do grupo com os menores níveis de morbidade e gravidade podem obter redução no pagamento do SAT de até $50 \%{ }^{8,9}$.

Por outro lado, se em decorrência do maior grau de acidentalidade os seus indicadores de morbidade previdenciária sejam enquadrados no grupo de pior desempenho entre as outras empresas de seu ramo de atividade econômica, poderá ter as alíquotas incidentes sobre a folha de pagamento de pessoal referentes aos Riscos Ambientais de Trabalho (RAT), a nova denominação do SAT oneradas ao dobro ${ }^{8,9}$.

Portanto, o FAP se coloca como um mecanismo econômico indutor para as empresas incrementarem medidas que aumentem a segurança no trabalho, aproximando o seu desempenho da sua responsabilidade social, esta última definida como a "obrigação de uma organização em maximizar seu impacto positivo no longo prazo, e minimizar seu impacto negativo sobre a sociedade" ${ }^{10}$. A responsabilidade social empresarial se relaciona com a perspectiva de melhoria contínua dos processos de trabalho e das relações com a comunidade, tendo como foco o bem-estar dos trabalhadores ${ }^{10,11}$.

Trazer ao centro das discussões a evolução das taxas de acidentalidade ocupacional e o eventual efeito que as medidas implementadas pelo Estado podem ter na sua redução, pode ser uma contribuição para que a lógica das relações de trabalho seja revista. A perspectiva de que estas medidas - incluindo-se entre elas o FAP - possam induzir as empresas a optarem por estratégias de seleção de ações mais efetivas no âmbito da saúde e segurança do trabalho (SST), pode ter, como efeito direto, a redução da acidentalidade ocupacional em geral.

Esforços de pesquisa focados na análise da realidade podem produzir conhecimentos que orientem a ação dos tomadores de decisão públicos e privados. $\mathrm{O}$ estudo da tendência temporal da acidentalidade ocupacional reveste-se, assim, de importância para o meio acadêmico. Por ser um tema relativamente novo e pouco estudado, as suas relações com as decisões dos empregadores no âmbito da SST ainda não foram suficientemente esclarecidas.

Assim, a presente pesquisa procurou comparar a evolução do risco de acidentes de trabalho no Brasil no período anterior (2006-2009) e posterior à vigência do FAP (2010-2016) segundo as variáveis disponíveis nas bases de dados da Previdência Social.

\section{Métodos}

Trata-se de um estudo observacional do tipo ecológico, que utilizou dados secundários referentes aos trabalhadores brasileiros com vínculo previdenciário, que sofreram algum tipo de acidente ocupacional registrado nas bases de dados da Previdência Social (Anuários Estatísticos da Previdência Social - AEPS e Anuários Estatísticos de Acidentes de Trabalho - AEAT) no período de 2006 a 2016.

O desenvolvimento deste trabalho foi feito em três etapas. A primeira consistiu em coletar os dados de interesse utilizando como fonte a Base de Dados Históricos de Acidentes de Trabalho disponíveis no site da Previdência Social, realizada com o apoio da ferramenta de extração e tabulação Infologo ${ }^{12}$. Foram selecionados os acidentes de trabalho registrados no Brasil entre os anos de 2006 e 2016 por grandes regiões brasileiras, classe do CNAE, motivo/situação, capítulos de CID10, sexo e idade. Também foram coletados o número médio de vínculos para cada ano segundo grandes regiões brasileiras, classe do CNAE, motivo/ situação, capítulos de CID10, sexo e idade, a fim de calcular as taxas de risco para cada variável.

Na segunda etapa os dados foram tabulados, realizando-se o cálculo das taxas de risco de acordo com a equação: Taxa de risco = (número de acidentes de trabalho [ano, grande região, CNAE, motivo/situação, CID10, sexo, idade] / número médio de vínculos [ano, grande região, CNAE, motivo/situação, CID10, sexo, idade]) x 1000. As informações foram organizadas em forma de tabelas utilizando o programa Microsoft Office Excel, e posteriormente analisadas utilizando-se o Software IBM - SPSS versão 19.0.

Para a análise estatística foram utilizadas as taxas dos dois períodos, que foram comparadas pelos testes $X$ quadrado e t de Student. A relação tempo-evento foi estabelecida pela correlação de Spearman e a regressão linear simples de Pearson (valor Beta). O nível de significância adotado foi de $\mathrm{p}<0,05$.

\section{Resultados}

O presente estudo buscou analisar a possível relação dos efeitos da implantação do FAP na evolução dos registros de acidentes de trabalho da base de dados da Previdência Social, considerando toda a força de trabalho formalizada brasileira com vínculo pela Consolidação das Leis do Trabalho (CLT). Para o período entre 2006 e 
2009 (anterior a implantação do FAP) a população anual média de trabalhadores estudada foi de 30.471 .666 vínculos empregatícios, com em média anual de 665.275 registros de acidentes de trabalho, uma taxa média de acidentalidade de 21,74 acidentes/ 1.000 trabalhadores.

O período sob efeito do Fator Acidentário de Prevenção - 2010-2016 - apresentou média de 41.311.474 trabalhadores por ano, com uma média de 683.338 registros de acidentes de trabalho ao ano, totalizando uma taxa de acidentalidade média de 16,61 acidentes de trabalho/1.000 trabalhadores para o período ( $\mathrm{p}$-valor $<0,0001$ ).

\section{Evolução da taxa de acidentes de trabalho segundo grande região de ocorrência}

É possível observar que no período anterior à implantação do FAP houve uma tendência de aumento das taxas de acidentalidade da força de trabalho formalizada brasileira, confirmados pelos valores de Spearman e Beta, que foram positivos para todas as grandes regiões de ocorrência (Tabela 1), apesar da falta de significância (exceto os resultados da região Nordeste). Em contrapartida, a partir de ano de 2010, no período de vigência do FAP, ocorreu uma significativa tendência de queda nas taxas anuais de risco de acidentes de trabalho ( $p$-valor $<0,001$ ), com os valores de Spearman e Beta fortemente negativos para todas as regiões e para o país como um todo. Considerando o período sob influência do FAP (2010-2016), houve uma redução média de 1,125 acidentes por ano para cada grupo de 1.000 trabalhadores no Brasil, ou seja, uma redução média de $40,63 \%$ em relação à média do período anterior à vigência do FAP.

\section{Evolução da taxa de acidentes de trabalho por divisão do CNAE}

Considerando as divisões do CNAE (Tabela 2) com maior número de acidentes registrados, é possível notar que no período 2006-2009, todas as atividades apresentaram tendência de aumento da taxa de acidentalidade da força de trabalho formalizada brasileira, corroborado pelo valor de Spearman positivo, exceto o setor primário,

Tabela 1. Taxa de acidentes de trabalho (x1.000 trab.) segundo ano de registro e grande região de ocorrência. Brasil, 2006-2016.

\begin{tabular}{|c|c|c|c|c|c|c|}
\hline Ano & Norte & Nordeste & Centro-Oeste & Sudeste & Sul & Brasil \\
\hline 2006 & 15,95 & 11,12 & 15,88 & 17,91 & 14,2 & 19,27 \\
\hline 2007 & 18,76 & 13,44 & 18,35 & 21,85 & 17,73 & 22,5 \\
\hline 2008 & 18,23 & 14,34 & 19,2 & 23,87 & 18,38 & 23,55 \\
\hline 2009 & 18,04 & 14,61 & 17,51 & 22,13 & 16,96 & 21,64 \\
\hline Média & 17,75 & 13,38 & 17,74 & 21,44 & 16,82 & 21,74 \\
\hline VMA\% & 0,05 & 0,11 & 0,04 & 0,08 & 0,07 & 0,04 \\
\hline Spearman & 0,200 & 1,00 & 0,400 & 0,800 & 0,400 & 0,400 \\
\hline Beta & 0,627 & 0,753 & 0,477 & 0,386 & 0,440 & 0,409 \\
\hline p-valor & 0,400 & 0,074 & 0,477 & 0,247 & 0,373 & 0,422 \\
\hline 2010 & 15,51 & 13,03 & 15,89 & 19,65 & 14,47 & 19,29 \\
\hline 2011 & 15,09 & 12,24 & 15,21 & 18,07 & 13,54 & 18,23 \\
\hline 2012 & 13,8 & 10,84 & 14,37 & 16,6 & 12,81 & 17,03 \\
\hline 2013 & 13,45 & 10,24 & 14,05 & 16,83 & 12,69 & 16,93 \\
\hline 2014 & 12,73 & 9,69 & 13,25 & 16,25 & 11,91 & 16,24 \\
\hline 2015 & 11,62 & 8,37 & 11,87 & 14,37 & 10,81 & 14,41 \\
\hline 2016 & 10,71 & 7,92 & 11,4 & 13,81 & 10,63 & 14,11 \\
\hline Média & 13,27 & 10,33 & 13,72 & 16,51 & 12,41 & 16,61 \\
\hline VMA\% & $-0,06$ & $-0,08$ & $-0,06$ & $-0,06$ & $-0,06$ & $-0,06$ \\
\hline Spearman & $-1,00$ & $-1,00$ & $-1,00$ & $-0,964$ & $-1,00$ & $-1,00$ \\
\hline$\beta e t a$ & $-1,231$ & $-1,139$ & $-1,290$ & $-1,038$ & $-1,523$ & $-1,125$ \\
\hline p-valor & $<0,001$ & $<0,001$ & $<0,001$ & $<0,001$ & $<0,001$ & $<0,001$ \\
\hline
\end{tabular}


Tabela 2. Taxa de acidentes de trabalho (x1.000 trab.) segundo ano e divisões do CNAE. Brasil, 2006-2016.

\begin{tabular}{|c|c|c|c|c|c|c|c|c|}
\hline Ano & $\begin{array}{l}\text { Ativ. } \\
\text { Saúde }\end{array}$ & Comércio & $\begin{array}{c}\text { Fabr. } \\
\text { Alimentos }\end{array}$ & $\begin{array}{c}\text { Transp. } \\
\text { Terre. }\end{array}$ & $\begin{array}{c}\text { Setor } \\
\text { Primário }\end{array}$ & $\begin{array}{c}\text { Comércio } \\
\text { Exc. Veículos }\end{array}$ & $\begin{array}{c}\text { Constr. } \\
\text { Edifícios }\end{array}$ & $\begin{array}{c}\text { Obras } \\
\text { Infraestr. }\end{array}$ \\
\hline 2006 & 1,4 & 1,59 & 1,67 & 0,78 & 1,05 & 0,55 & 0,44 & 0,48 \\
\hline 2007 & 1,52 & 1,89 & 1,94 & 0,9 & 0,85 & 0,67 & 0,5 & 0,57 \\
\hline 2008 & 1,57 & 2,01 & 1,99 & 0,98 & 0,78 & 0,71 & 0,65 & 0,7 \\
\hline 2009 & 1,63 & 1,89 & 1,79 & 0,93 & 0,75 & 0,64 & 0,65 & 0,68 \\
\hline Média & 1,53 & 1,85 & 1,85 & 0,9 & 0,86 & 0,64 & 0,56 & 0,61 \\
\hline VMA\% & 0,05 & 0,06 & 0,03 & 0,06 & $-0,1$ & 0,06 & 0,15 & 0,13 \\
\hline Spearman & 1,00 & 0,632 & 0,4 & 0,8 & -1 & 0,4 & 0,949 & 0,8 \\
\hline p-valor & $<0,001$ & 0,371 & 0,607 & 0,204 & $<0,001$ & 0,599 & 0,512 & 0,196 \\
\hline 2010 & 1,54 & 1,54 & 1,54 & 1,71 & 0,97 & 0 & 0,67 & 0,59 \\
\hline 2011 & 1,52 & 1,64 & 1,32 & 0,76 & 0,58 & 0,56 & 0,66 & 0,55 \\
\hline 2012 & 1,52 & 1,5 & 1,18 & 0,72 & 0,53 & 0,54 & 0,66 & 0,57 \\
\hline 2013 & 1,58 & 1,52 & 1,13 & 0,71 & 0,47 & 0,53 & 0,63 & 0,53 \\
\hline 2014 & 1,51 & 1,17 & 0,94 & 0,51 & 0,45 & 0,44 & 0,45 & 0,48 \\
\hline 2015 & 1,62 & 1,17 & 0,98 & 0,54 & 0,4 & 0,47 & 0,44 & 0,4 \\
\hline 2016 & 1,69 & 1,2 & 0,93 & 0,52 & 0,37 & 0,45 & 0,35 & 0,31 \\
\hline Média & 1,57 & 1,39 & 1,15 & 0,78 & 0,54 & 0,43 & 0,55 & 0,49 \\
\hline VMA\% & 0,01 & $-0,05$ & $-0,08$ & $-0,17$ & $-0,15$ & $-0,04$ & $-0,07$ & $-0,07$ \\
\hline Spearman & 0,52 & $-0,81$ & $-0,96$ & $-0,89$ & $-1,00$ & $-0,14$ & $-0,99$ & $-0,96$ \\
\hline p-valor & 0,23 & 0,03 & $<0,001$ & $<0,001$ & $<0,001$ & 0,76 & $<0,001$ & $<0,001$ \\
\hline
\end{tabular}

que apresentou forte tendência de decréscimo da taxa de acidentes de trabalho. Entre os agregados de atividades econômicas estudados, somente as atividades de saúde e o setor primário apresentaram significância estatística. Após a implantação do FAP, a tendência de queda da taxa de acidentalidade foi notável em todos os setores, com o índice de Spearman negativo, exceto nas atividades de saúde. Nesse período os resultados apresentaram significância estatística para a maioria dos setores, excluindo-se as atividades de saúde e o comércio exceto veículos.

\section{Evolução da taxa de acidentes de trabalho segundo motivo - situação}

Levando em consideração a acidentalidade segundo motivo - situação (Tabela 3), nota-se que antes da implantação do FAP já havia uma tendência de queda nas taxas de acidentes de trabalho típico com CAT, trajeto com CAT e doença com CAT, confirmados pelos índices de Spearman e Beta negativos, e uma tendência de aumento nos acidentes sem CAT, pelo Spearman positivo. Dentre estes, somente os acidentes tí- picos com CAT e doença com CAT obtiveram significância. No período sob influência do FAP ocorreu tendência de queda nas taxas de acidentalidade dos acidentes típicos com CAT, doença ocupacional com CAT e acidentes sem CAT, todos com significância estatística. Na direção contrária, os acidentes de trajeto com CAT apresentaram tendência de crescimento, com Spearman e Beta positivos, porém sem significância estatística para o período.

\section{Evolução da taxa de acidentes de trabalho segundo capítulos do CID-10}

Em relação à acidentalidade segundo os principais capítulos do CID10 (Tabela 4), considerando-se as taxas de acidentalidade, no período de 2006 e 2009 houve uma tendência de aumento para a maioria dos capítulos analisados, obtendo-se Spearman positivo, exceto para os capítulos XIX e XX que apresentaram Spearman negativo. Neste período somente os acidentes classificados nos capítulos XX e XXI obtiveram significância estatística. Já no período sob influência do FAP, houve tendência de redução dos acidentes pelos 
Tabela 3. Taxa de acidentes de trabalho (x1.000 trab.) segundo ano e motivo situação. Brasil, 2006-2016.

\begin{tabular}{|c|c|c|c|c|c|}
\hline Ano & Típico CAT & Trajeto CAT & Doença CAT & Sem CAT & Total \\
\hline 2006 & 15,33 & 2,81 & 1,14 & 0 & 19,27 \\
\hline 2007 & 14,23 & 2,7 & 0,76 & 4,81 & 22,5 \\
\hline 2008 & 13,76 & 2,76 & 0,63 & 6,38 & 23,55 \\
\hline 2009 & 12,52 & 2,66 & 0,58 & 5,87 & 21,64 \\
\hline Média & 13,96 & 2,73 & 0,78 & 4,27 & 21,74 \\
\hline VMA\% & $-0,06$ & $-0,02$ & $-0,19$ & 0,12 & 0,04 \\
\hline Spearman & -1 & $-0,8$ & -1 & 0,8 & 0,4 \\
\hline Beta & $-1,095$ & $-14,914$ & $-4,702$ & 0,376 & 0,409 \\
\hline p-valor & 0,013 & 0,237 & 0,077 & 0,151 & 0,422 \\
\hline 2010 & 11,34 & 2,59 & 0,47 & 4,88 & 19,29 \\
\hline 2011 & 10,78 & 2,55 & 0,43 & 4,47 & 18,23 \\
\hline 2012 & 10,16 & 2,46 & 0,4 & 4 & 17,03 \\
\hline 2013 & 10,13 & 2,62 & 0,4 & 3,78 & 16,93 \\
\hline 2014 & 9,82 & 2,65 & 0,4 & 3,38 & 16,24 \\
\hline 2015 & 8,93 & 2,47 & 0,36 & 2,65 & 14,41 \\
\hline 2016 & 8,63 & 2,64 & 0,3 & 2,54 & 14,11 \\
\hline Média & 9,97 & 2,57 & 0,39 & 3,67 & 16,61 \\
\hline VMA\% & $-0,05$ & $-0,01$ & $-0,05$ & $-0,11$ & $-0,06$ \\
\hline Spearman & $-1,00$ & 0,36 & $-0,96$ & $-1,00$ & $-1,00$ \\
\hline Beta & $-2,215$ & 4,907 & $-37,85$ & $-2,438$ & $-1,129$ \\
\hline p-valor & $<0,001$ & 0,703 & 0,002 & $<0,001$ & $<0,001$ \\
\hline
\end{tabular}

VMA\%=Variação Média Anual percentual; Spearman=Coeficiente de Correlação de Spearman; ßeta=Variação Média Anual por regressão linear de Pearson; p-valor (ANOVA); CAT=Comunicação de Acidente de Trabalho.

Fonte: Elaborado pelos autores, adaptado de Infologo da Previdência Social ${ }^{12}$.

capítulos XIX, XIII e “outros”. Todas as séries de taxas apresentaram significância estatística entre 2010 e 2016.

\section{Evolução da taxa de acidentes de trabalho segundo sexo e faixa etária}

Observando-se as taxas de acidentalidade da força de trabalho formalizada brasileira segundo o sexo, no período de 2006 a 2009 não houve tendência de aumento do risco nos dois sexos, com índices de Spearman e Beta positivos, sem significância estatística. Em contrapartida, no período após a implantação do FAP houve uma forte tendência de queda das taxas, com Spearman e Beta negativos, e significância estatística para ambos os sexos (Tabela 5).

Ao considerarem-se as taxas de acidentalidade por faixa etária do trabalhador formalizado brasileiro, é possível notar uma tendência de aumento das mesmas no período de 2006 a 2009, exceto para faixa etária até 19 anos. Nesse período houve significância somente nos extremos de idade - até 19 anos e de 60 a 69 anos. Para o período após implantação do FAP houve uma forte tendência de queda das taxas de acidentalidade, com valores de Spearman e Beta negativos para todas as faixas etárias, exceto acima dos 70 anos, única faixa sem significância estatística (Tabela 5).

\section{Discussão}

O Decreto 6.042/2007 instituiu a aplicação, acompanhamento e avaliação do Fator Acidentário de Prevenção (FAP) e do Nexo Técnico Epidemiológico, por meio da inclusão do artigo 202A no Regulamento da Previdência Social. Como é sabido, o FAP foi uma das medidas criadas para incentivar a melhoria das condições de trabalho, sendo que os dados utilizados como fonte para a geração do FAP possuem caráter temporário, o universo dos dados utilizados para o cálculo dos índices de frequência, gravidade e custo referem-se a dados individualizados por empresa, são recalculados bianualmente e essa dinâmica estimula o investimento em saúde e segurança no ambiente de trabalho ${ }^{10-13}$.

Como se pode observar a partir dos resultados apresentados, houve uma significativa redução 
Tabela 4. Taxa de acidentes de trabalho (x1.000 trab.) segundo ano e capítulo do CID10. Brasil, 2006-2016.

\begin{tabular}{lrrrrrr}
\hline \multicolumn{1}{c}{ Ano } & CapXIX & CapXIII & CapXX & CapV & CapXXI & Outros \\
\hline 2006 & 15,37 & 2,01 & 0,6 & 0,17 & 0,22 & 0,9 \\
2007 & 15,8 & 4,22 & 0,58 & 0,38 & 0,24 & 1,28 \\
2008 & 16,29 & 4,46 & 0,55 & 0,55 & 0,27 & 1,43 \\
2009 & 15,12 & 3,82 & 0,54 & 0,52 & 0,31 & 1,33 \\
Média & 15,65 & 3,63 & 0,57 & 0,41 & 0,26 & 1,24 \\
VMA\% & 0 & 0,34 & $-0,03$ & 0,54 & 0,12 & 0,16 \\
Spearman & $-0,2$ & 0,4 & -1 & 0,8 & 1 & 0,8 \\
p-valor & 0,802 & 0,607 & $<0,001$ & 0,203 & $<0,001$ & 0,196 \\
2010 & 13,79 & 3,15 & 0,51 & 0,43 & 0,33 & 1,08 \\
2011 & 13,08 & 2,85 & 0,5 & 0,41 & 0,39 & 1 \\
2012 & 12,19 & 2,54 & 0,51 & 0,41 & 0,45 & 0,92 \\
2013 & 12,06 & 2,49 & 0,54 & 0,45 & 0,49 & 0,9 \\
2014 & 11,56 & 2,31 & 0,54 & 0,44 & 0,56 & 0,85 \\
2015 & 10,23 & 1,9 & 0,54 & 0,45 & 0,59 & 0,71 \\
2016 & 10,05 & 1,77 & 0,55 & 0,46 & 0,63 & 0,65 \\
Média & 11,85 & 2,43 & 0,53 & 0,44 & 0,49 & 0,87 \\
VMA\% & $-0,06$ & $-0,09$ & 0,01 & 0,01 & 0,12 & $-0,08$ \\
Spearman & $-1,00$ & $-1,00$ & 0,898 & 0,818 & 1,00 & $-1,00$ \\
p-valor & $<0,001$ & $<0,001$ & 0,006 & 0,024 & $<0,001$ & $<0,001$ \\
\hline
\end{tabular}

VMA\%=Variação Média Anual percentual; Spearman=Coeficiente de Correlação de Spearman; ßeta=Variação Média Anual por regressão linear de Pearson; p-valor (ANOVA); CapXIX=Lesões, envenenamentos e outras consequências de causas externas; CapXIII=Doenças do Sistema Osteomuscular e conjuntivo; CapXX=Causas externas de morbidade e mortalidade; $\mathrm{CapV=Transtornos}$ mentais e comportamentais; CapXXI=Fatores que influenciam o estado de saúde e o contato com os serviços de saúde.

Fonte: Elaborado pelos autores, adaptado de Infologo da Previdência Social ${ }^{12}$.

da taxa de acidentalidade no período de vigência do FAP, que pode indicar algum efeito positivo decorrente de sua implementação. Apesar da impossibilidade de afirmações de causalidade em razão da metodologia utilizada, a tendência de redução das taxas de risco observada nos resultados desta pesquisa ocorreu especialmente após o início da vigência do FAP. É inegável, também, que o mecanismo de bônus/ônus incorporado à metodologia de cálculo das alíquotas para o pagamento do Riscos Ambientais do Trabalho (RAT) pode induzir as empresas a considerarem investimentos mais efetivos no âmbito da saúde e segurança dos ambientes laborais visando redução de custos com encargos sociais ${ }^{11,13}$.

Deve-se salientar que houve uma evolução crescente da força de trabalho tanto no primeiro quanto no segundo períodos analisados. Entretanto, no segundo período essa tendência se manteve somente até o ano de 2014, quando houve redução do número de vínculos empregatícios formais. A recessão econômica e a consequente tendência de redução da força de trabalho empregada podem produzir efeitos sobre o perfil dos trabalhadores, e também sobre o risco de acidentalidade, já que o perfil dos desempregados não é o mesmo dos que mantiveram seu emprego na recessão. $O$ viés de seleção produzido por esta disparidade decorre do fato de que o principal grupo que sofre com o desemprego é o da força de trabalho jovem. Isso já foi reforçado por Da Cruz Vilas ${ }^{13}$, ao verificar que os principais atingidos pelo desemprego em Portugal eram os jovens, principalmente os menos escolarizados. Os trabalhadores jovens costumam ter risco aumentado para a acidentalidade ocupacional por se concentrar nas atividades de maior risco, estar em período probatório ou com vínculo experimental, e possuir menos experiência cognitiva e psicológica, segundo a Agência Europeia para a Saúde e Segurança no Trabalho ${ }^{14}$. Assim, a queda da taxa de acidentalidade observada pode ter sido influenciada por esta particularidade do mercado de trabalho. Porém, de encontro com esta constatação, os dados observados neste trabalho demonstraram que a faixa etária que apresentou as maiores taxas de risco para a acidentalidade ocupacional no Brasil foi a dos trabalhadores entre 50 e 59 anos. Por este motivo, as explicações para a redução significativa nas taxas de aciden- 
Tabela 5. Taxa de acidentes de trabalho (x1.000 trab.) segundo ano, sexo e faixa etária. Brasil, 2006-2016.

\begin{tabular}{|c|c|c|c|c|c|c|c|c|c|}
\hline Ano & Masc. & Fem. & Até 19a & $20 a 29 a$ & $30 a 39 a$ & $40 \mathrm{a} 49 \mathrm{a}$ & $50 a 59 a$ & $60 a 69 a$ & 70mais \\
\hline 2006 & 24,36 & 12,57 & 23,29 & 21,32 & 19,34 & 19,23 & 18,5 & 12,81 & 6,08 \\
\hline 2007 & 27,45 & 16,45 & 23,17 & 23,55 & 22,38 & 23,75 & 25,61 & 18,58 & 6,75 \\
\hline 2008 & 28,19 & 17,04 & 22,29 & 23,54 & 23,1 & 25,03 & 27,49 & 19,03 & 7,18 \\
\hline 2009 & 26,69 & 16,28 & 20,05 & 21,98 & 21,93 & 23,93 & 26,51 & 19,08 & 6,65 \\
\hline Média & 26,67 & 15,59 & 22,2 & 22,6 & 21,69 & 22,99 & 24,53 & 17,38 & 6,67 \\
\hline VMA\% & 0,03 & 0,1 & $-0,05$ & 0,01 & 0,05 & 0,08 & 0,14 & 0,16 & 0,03 \\
\hline Spearman & 0,400 & 0,400 & $-1,00$ & 0,200 & 0,400 & 0,800 & 0,800 & 1,00 & 0,400 \\
\hline Beta & 0,468 & 0,471 & $-0,784$ & 0,259 & 0,528 & 0,389 & 0,258 & 0,345 & 1,740 \\
\hline p-valor & 0,398 & 0,257 & 0,088 & 0,774 & 0,331 & 0,226 & 0,182 & 0,185 & 0,390 \\
\hline 2010 & 23,97 & 14,72 & 19,11 & 20,05 & 19,57 & 21,41 & 23,07 & 16,47 & 7,07 \\
\hline 2011 & 22,57 & 14,07 & 16,08 & 18,9 & 18,61 & 20,28 & 21,92 & 15,56 & 7,34 \\
\hline 2012 & 21,05 & 13,19 & 14,14 & 17,58 & 17,53 & 19,01 & 20,09 & 14,55 & 5,73 \\
\hline 2013 & 20,46 & 13,25 & 13,87 & 16,9 & 17,33 & 18,71 & 19,89 & 14,49 & 7,28 \\
\hline 2014 & 19,34 & 12,64 & 12,83 & 16,08 & 16,47 & 17,63 & 18,36 & 13,75 & 6,88 \\
\hline 2015 & 17,23 & 11,51 & 10,84 & 14,44 & 14,88 & 15,58 & 16,29 & 12,32 & 6,61 \\
\hline 2016 & 16,79 & 11,36 & 10,77 & 14,35 & 14,6 & 15,4 & 15,92 & 12,17 & 6,51 \\
\hline Média & 20,2 & 12,96 & 13,95 & 16,9 & 17 & 18,29 & 29,36 & 14,19 & 6,77 \\
\hline VMA\% & $-0,06$ & $-0,05$ & $-0,11$ & $-0,06$ & $-0,05$ & $-0,06$ & $-0,07$ & $-0,06$ & 0,00 \\
\hline Spearman & $-1,00$ & $-0,964$ & $-1,00$ & $-1,00$ & $-1,00$ & $-1,00$ & $-1,00$ & $-1,00$ & $-0,500$ \\
\hline Beta & $-0,812$ & $-1,706$ & $-0,705$ & $-0,997$ & $-1,164$ & $-0,944$ & $-0,794$ & $-1,339$ & $-1,069$ \\
\hline p-valor & $<0,001$ & $<0,001$ & $<0,001$ & $<0,001$ & $<0,001$ & $<0,001$ & $<0,001$ & $<0,001$ & 0,550 \\
\hline
\end{tabular}

VMA\%=Variação Média Anual percentual; Spearman=Coeficiente de Correlação de Spearman; ßeta=Variação Média Anual por regressão linear de Pearson; p-valor (ANOVA); Masc.=Masculino; Fem.=Feminino; a=anos.

Fonte: Elaborado pelos autores, adaptado de Infologo da Previdência Social ${ }^{12}$.

talidade no período citado permanecem abertas, e os efeitos da implantação da metodologia do FAP não podem ser descartados.

No sentido contrário, poder-se-ia considerar ainda o possível efeito de um outro macroprocesso bastante evidente nas relações de trabalho recentes, caso da flexibilização do trabalho, constatado pela tendência à terceirização do trabalho, com aumento da subcontratação de mão de obra, o que tem sido associado com o aumento do risco de acidentalidade ocupacional pelo aumento da rotatividade, falta de experiência e familiaridade com os equipamentos e exigências das tarefas da força de trabalho terceirizada ${ }^{15,16}$, além da redução do controle pelos órgãos públicos e tendência à desresponsabilização das empresas com a saúde e segurança no trabalho ${ }^{17}$.

Outra característica dos períodos recessivos que pode levar à redução da acidentalidade ocupacional é o que poderia ser chamado de viés de exposição, que decorre do aumento da ociosidade das empresas, que ao mesmo tempo se obrigam a manter um núcleo técnico empregado, mas com menor tempo de exposição aos riscos de suas atividades ${ }^{18}$. Esta circunstância tende a reduzir o risco da acidentalidade na população que se manteve empregada neste período.

Outro ponto importante a ser observado é o aumento dos acidentes de trajeto após a implantação do FAP (Tabela 3). Vale ressaltar que os acidentes de trabalho de trajeto são aqueles que ocorrem entre a residência e o local de trabalho, portanto não sofrem influência direta de fatores controlados pela gestão de saúde e segurança do trabalho. Esta mesma tendência já foi observada por Almeida et al. ${ }^{19}$ no período de 1998 e 2008, o qual acredita que essa pode estar associada com o aumento da violência urbana, aumento do número de veículos por 100 mil habitantes ou ainda pela maior prevalência das motocicletas como meio de transporte. A relativa independência das taxas de acidentalidade de trajeto e a tendência de aumento observada no período de vigência do FAP pode ser um indício de que o sistema de registro de CAT permaneceu funcionando com suas características habituais, o que valoriza a ideia de que foram as medidas de ampliação das ações de controle dos fatores de risco ocupacio- 
nais que explicaram, pelo menos parcialmente, a redução do risco de acidentes típicos e de doenças ocupacionais. Cabe ressaltar que estes autores, utilizando a mesma metodologia, chegaram aos mesmos resultados desta pesquisa em relação à evolução de outros tipos de acidentes: houve tendência significativa de decréscimo nas taxas de incidência de acidentes de trabalho em geral, o mesmo ocorrendo para os acidentes de trabalho típicos, com aumento do número absoluto de registros. Os autores apontaram como fatores contribuintes para o declínio das taxas de incidência de acidentes de trabalho e de mortalidade por esta causa a melhoria das condições de trabalho, o maior crescimento do setor de serviços do que o setor industrial, subnotificação dos acidentes de trabalho e terceirização dos serviços ${ }^{19,20}$.

É importante destacar ainda que, no período anterior à implementação do FAP, está incluso o ano de 2006, que não contemplava a metodologia do NTEP. Como já citado anteriormente, esta metodologia, implantada em abril de 2007, incorporou um filtro associando estatisticamente os riscos das atividades econômicas com patologias responsáveis por incapacidade para o trabalho, acrescentando a lógica do nexo coletivo dos afastamentos laborais com o trabalho. Assim, após sua implantação observou-se um aumento do número de acidentes de trabalho na ordem de $45,99 \%$ entre 2006 e 2008, basicamente às custas dos registros sem emissão de CAT (86\%), segundo análise feita por Silva-Junior et al. ${ }^{20}$. Esses fatos podem explicar a redução da tendência de registros com CAT e o aumento das taxas de acidentalidade para o período, observados na Tabela 3.

O NTEP, em linhas gerais, é o reconhecimento das limitações do nexo técnico previdenciário (NTP), que sustentava isoladamente a lógica classificatória da Previdência Social até 2006, e a inclusão, como eventos acidentários, de incapacidades ocorridas em decorrência da significância estatística, entre diversos tipos de doenças e uma determinada atividade econômica, e que foram encaminhadas para concessão de benefício previdenciário (sem nexo com o trabalho) pelas empresas $^{21}$. Sabe-se que somente a CAT não é uma fonte fidedigna de notificação, uma vez que o registro de acidentes de trabalho, apesar de obrigatório, fica sujeito ao interesse do patrão, que tende à subnotificação. Neste sentido, estudo de validação de casos de nexo realizados pelo filtro epidemiológico do NTEP apontou a sua institucionalização como um avanço no estabelecimento do nexo trabalho-doença no âmbito previdenciário, indicando que ele ampliou e diversificou diag- nósticos anteriormente subnotificados, apesar de salientar a necessidade da perícia médica para sua confirmação, juntamente com a sugestão de visitas in loco aos locais de trabalho dos trabalhadores afastados ${ }^{20}$. Isso foi claramente demonstrado com os dados da Previdência Social referentes aos capítulos V (Transtornos Mentais) e XIII (Doenças dos Sistema Osteomuscular) da CID-10 um ano após a incorporação da metodologia do filtro epidemiológico aos registros de afastamentos laborais, que apresentaram respectivamente um crescimento de $1.578 \%$ e de $517 \%$ nos registros ${ }^{21}$.

Pelo exposto, considerando os resultados obtidos e apresentados neste trabalho, é inegável a constatação de que praticamente em todas as variáveis relacionadas à acidentalidade ocupacional estudadas - grande região de ocorrência, divisão do CNAE, motivo-situação, capítulos do CID-10, sexo e faixa etária - houve forte tendência de queda nas taxas de acidentalidade ocupacional concomitantemente à vigência do FAP, confirmada pela forte significância estatística na maioria das séries de taxas analisadas ( $\mathrm{p}$-valor $<0,05$ ), o que pode, entre outras possibilidades explicativas, indicar o efeito virtuoso da implantação do FAP na redução da acidentalidade em decorrência do interesse das empresas em realizar investimentos mais efetivos no controle de fatores de risco nos ambientes de trabalho realizados pelas empresas.

Apesar disso, diversos outros fatores e hipóteses podem ser cogitadas como explicações concorrentes à aqui apresentada. Por isso, outros estudos com este tema são necessários para controlar melhor os diferentes vieses que podem ter afetado os resultados obtidos, e esclarecer de forma mais consistente as relações de causalidade que expliquem o comportamento comprovado nesta pesquisa: a tendência de redução do risco de acidentes de trabalho na população formalizada de trabalhadores brasileiros no período de 2010 a 2016.

\section{Conclusões}

A pesquisa realizada observou tendência indefinida na evolução da maioria das séries de taxas de acidentes de trabalho estudadas antes da vigência da metodologia do FAP (2006-2009). Por outro lado, praticamente todas as séries de taxas analisadas durante a vigência do FAP (2010-2016) foram de forte redução, com diferenças estatisticamente significativa entre os dois períodos.

Considerando as limitações metodológicas deste estudo de cunho exploratório, não é possí- 
vel afirmar a causalidade dos achados apresentados, mas o FAP incorpora uma lógica de indução a investimentos mais efetivos em saúde e segurança do trabalho que pode ter contribuído para os resultados obtidos.

\section{Colaboradores}

AR Wernke trabalhou com metodologia, pesquisa, análise e interpretação dos dados, referencial bibliográfico, designer e texto final. MCL Teixeira trabalhou com tradução, referencial bibliográfico e revisão final. BO Kock trabalhou com a tradução, referencial bibliográfico e revisão final. OLO Sousa trabalhou com referencial bibliográfico e revisão final. ACMC Melo trabalhou com referencial bibliográfico e revisão final. TM Sakae trabalhou com metodologia, análise estatística, interpretação dos dados e revisão do texto final. FRL Magajewski trabalhou com orientação, metodologia, análise, interpretação dos dados e revisão do texto final.

\section{Referências}

1. Cassar VB. Direito do trabalho: de acordo com a reforma trabalhista e a MP 808/2017. 15ª ed. Rio de Janeiro: Método; 2018.

2. Cardoso EM. Saúde e segurança no trabalho: um direito constitucional [Internet]. Conteúdo Jurídico; 2014 [acessado 2018 set 13]. Disponível em: http://www. conteudojuridico.com.br/?artigos\&ver $=2.51309 \&$ $\operatorname{seo}=1$.

3. Teixeira S. A depressão no meio ambiente do trabalho e sua caracterização como doença do trabalho. Rev Trib Reg Tra 2007; 46(76):27-44.

4. Brasil. Lei no 8.213, de 24 de julho de 1991. Dispõe sobre os Planos de Benefícios da Previdência Social e dá outras providências. Diário Oficial da União; 1991.

5. Sousa YG, Medeiro PC, Medeiros SM. Importância da relação existente entre o acidente de trabalho e o nexo técnico epidemiológico (NTEP). Enferm Rev 2016; 17(1):3-13.

6. Brasil. Lei no 10.666 , de 8 de maio de 2003. Dispõe sobre a concessão da aposentadoria especial ao cooperado de cooperativa de trabalho ou de produção e dá outras providências. Diário Oficial da União 2003; maio 9.

7. Matos AB, Hostensky EL. Fator Acidentário de Prevenção (FAP) e Nexo Técnico Epidemiológico Previdenciário (NTEP): Indicadores Para uma Intervenção Psicossocial. Psicol Soc 2016; 28(1):145-150.

8. Corrêa Filho HR. O Fator Acidentário Previdenciário como instrumento epidemiológico de controle de riscos do trabalho. Rev Bras Epidemiol 2005; 8(4):432439.

9. Giacchetti MCM, Nogueira PL, Gozzi MP. Responsabilidade Social, Segurança no Trabalho e Fator Acidentário de Prevenção (FAP): uma relação direta. Anais do III SINGEP e II S2IS [Internet]. 2014 [acessado 2018 set 6]. Disponível em: http://repositorio.uninove.br/xmlui/bitstream/handle/123456789/637/4. pdf? sequence $=1$.

10. Barbosa Filho NA. Segurança do Trabalho e Gestão Ambiental. São Paulo: Atlas; 2011.

11. Mazarin CR. A Concreção Eficacial do Fator Acidentário de Prevenção sob luz do artigo 10 da lei 10.666/2003 [dissertação]. São Paulo: Pontíficia Universidade Católica de São Paulo; 2016.
12. Previdência Social. AEAT InfoLogo Base de Dados Históricos de Acidentes de Trabalho [Internet]. [acessado 2018 set 13]. Disponível em: http://www3.dataprev. gov.br/aeat/.

13. Da Cruz Vilas BJ. Políticas Públicas e Desemprego Jovem [dissertação]. Covilhã: Universidade da Beira Interior; 2013.

14. Agência Europeia para a Segurança e Saúde no Trabalho (EU-OSHA). Os jovens e a segurança e saúde no trabalho [Internet]. [acessado 2020 mar 1]. Disponível em: https://osha.europa.eu/pt/themes/young-workers.

15. Frez GM, Mello VM. Terceirização no Brasil. SADSJ 2016; 2(4):78-101.

16. Costa de Sá EVH. Sociedade de Consumo, Globalização e Precarização das Relações Laborais na Terceirização. Rev Direito Trab Meio Amb Trab 2016; 2(2):195-208.

17. Costa MS. Terceirização no Brasil: velhos dilemas e a necessidade de uma ordem mais includente. Cad EBAPE 2017; 15(1):115-131.

18. Cruz FIL. Flutuações na Produção industrial gaúcha e o atual cenário recessivo. Indicadores Econômicos FEE 2017; 45(1):21-34.

19. Almeida FSS, Morrone LC, Ribeiro KB. Tendências na incidência e mortalidade por acidentes de trabalho no Brasil, 1998 e 2008. Cad Saude Publica 2014; 30(9):1957-1964.

20. Silva-Junior JS, Almeida FSS, Morrone LC. Discussão dos Impactos do Nexo Técnico Epidemiológico Previdenciário. Rev Bras Med Trab 2012; 10(2):72-79.

21. Todeschini R, Codo W. Uma Revisão Crítica da Metodologia do Nexo Técnico Epidemiológico Previdenciário (NTEP). Rev Baiana Saude Publica 2013; 37(2):486-500.

Artigo apresentado em 13/04/2020

Aprovado em 21/07/2021

Versão final apresentada em 23/07/2021

Editores-chefes: Romeu Gomes, Antônio Augusto Moura da Silva 